\title{
SHB1/HY1 Alleviates Excess Boron Stress by Increasing BOR4 Expression Level and Maintaining Boron Homeostasis in Arabidopsis Roots
}

\section{Qiang Lv', Lei Wangt, Jin-Zheng Wang, Peng Li, Yu-Li Chen, Jing Du, Yi-Kun He* and Fang Bao*}

College of Life Sciences, Capital Normal University, Beijing, China

Boron is an essential mineral nutrient for higher plant growth and development. However, excessive amounts of boron can be toxic. Here, we report on the characterization of an Arabidopsis mutant, shb1 (sensitive to high-level of boron 1), which exhibits hypersensitivity to excessive boron in roots. Positional cloning demonstrated that the shb1 mutant bears a point mutation in a gene encoding a heme oxygenase $1(\mathrm{HO} 1)$ corresponding to the HY1 gene involved in photomorphogenesis. The transcription level of the SHB1/HY1 gene in roots is up-regulated under excessive boron stimulation. Either overexpressing SHB1/HY1 or applying the $\mathrm{HO} 1$ inducer hematin reduces boron accumulation in roots and confers high boron tolerance. Furthermore, carbon monoxide and bilirubin, catalytic products of $\mathrm{HO} 1$, partially rescue the boron toxicity-induced inhibition of primary root growth in shb1. Additionally, the mRNA level of BOR4, a boron efflux transporter, is reduced in shb1 roots with high levels of boron supplementation, and hematin cannot relieve the boron toxicity-induced root inhibition in bor4 mutants. Taken together, our study reveals that $\mathrm{HO} 1$ acts via its catalytic by-products to promote tolerance of excessive boron by up-regulating the transcription of the BOR4 gene and therefore promoting the exclusion of excessive boron in root cells.

Keywords: Arabidopsis thaliana, heme oxygenase 1, carbon monoxide, bilirubin, BOR4, primary root elongation, excessive boron tolerance

\section{INTRODUCTION}

Boron (B), with low abundance but wide distribution in nature, is an essential micronutrient for plants and animals (Warington, 1923; Nielsen, 2008). Both boric acid and borate are able to form complexes involved in different cellular processes (Cakmak et al., 1995; Findeklee and Goldbach, 1996). Until now, the most widely accepted function of B is the formation of pectic substances. Borate crosslinks with apiose residues of rhamnogalacturonan II (RG-II), and this complex plays an essential role in cell wall structure and function (Kobayashi et al., 1996; O'Neill et al., 2004). Other functions of B have also been suggested, such as maintenance of membrane integrity, and metabolism of biomacromolecules (nucleic acids, carbohydrates, and proteins, etc.) (Blevins and Lukaszewski, 1998; Reid et al., 2004). 
Boron is taken up from soil by roots in the form of boric acid and is essential for plant growth within a narrow optimal range. Deficiency of boron results in severe defects in vegetative and reproductive growth (Shorrocks, 1997), while excessive boron causes toxic effects (Nable et al., 1997). Hence, it is important for plants to maintain a boron homeostasis for normal growth and development, and a complex system might be employed to regulate the absorption, mobility, distribution, and storage of $\mathrm{B}$ (Hänsch and Mendel, 2009).

Boron toxicity is a serious agricultural problem in semiarid areas all over the world (Camacho-Cristóbal et al., 2008). Toxic effects of boron might include inhibition of cell division and elongation, defects in cell wall development, and metabolic disruption (Reid et al., 2004). Although the toxicity symptoms can be diverse in aerial parts of plants, high boron has been reported to inhibit root growth of many species, including barley, Arabidopsis, and maize, by reducing the size of root meristems (Choi et al., 2007; Aquea et al., 2012; Esim et al., 2013).

Many plant species can reduce the toxic effects of excessive boron by reducing boron accumulation via root boron exclusion (Hayes and Reid, 2004; Hamurcu et al., 2016). Several transporter-encoding genes have been proven to play roles in tolerance to excessive boron, such as BOR4 in Arabidopsis (Miwa et al., 2007), Bot1 in barley (Sutton et al., 2007), and Bo1 and Bo4 in wheat (Pallotta et al., 2014). To date, the mechanism of boron uptake and distribution in plants has been well studied; however, our knowledge of the regulation mechanism for maintaining $\mathrm{B}$ homeostasis is still limited.

Heme oxygenase (HO; EC 1.14.99.3) is the rate-determining enzyme in the transformation of heme into biliverdin, which is then converted into bilirubin (BR) by biliverdin reductase. Heme degradation is accompanied by the release of free $\mathrm{Fe}$ and carbonic oxide (CO) (Wilks, 2002). Previous reports indicate that homologs of $\mathrm{HO}$ exist widely in different plant species, including Arabidopsis, rice, pea, tobacco, soybean, and tomato, similar to those found in humans, suggesting the evolutionary conservation of $\mathrm{HO}$ genes (Shekhawat and Verma, 2010).

Muramoto et al. (1999) cloned the first Arabidopsis HOencoding gene, HY1. Subsequently, three other HOs (HO2, $\mathrm{HO} 3$, and $\mathrm{HO} 4)$ were identified in the Arabidopsis genome. These four members of the $\mathrm{HO}$ family fall into two subfamilies: one subfamily contains $\mathrm{HY} 1 / \mathrm{HO} 1, \mathrm{HO} 3$, and $\mathrm{HO} 4$, while $\mathrm{HO} 2$ belongs to another subfamily (Gisk et al., 2010). Among them, HO1 has much higher mRNA abundance than the others and can be induced by various chemical and stress stimuli, such as salinity (Xie et al., 2011, 2013), heavy metals (Han et al., 2008, 2014), UV-B and UV-C (Yannarelli et al., 2006; Xie et al., 2012), $\mathrm{H}_{2} \mathrm{O}_{2}$ (Chen et al., 2009), and iron deficiency (Li et al., 2013; Yang et al., 2016). These data imply the indispensable protection roles of HOs and their enzymatic products in plant growth and development processes under hostile environmental conditions.

In this study, we identified an Arabidopsis mutant named shb1 (sensitive to high-level of boron 1) that showed major developmental defects in roots under high concentrations of boron. Positional cloning of the SHB1 gene indicated that the causative locus was an allele of the Arabidopsis thaliana HY1 gene. Pharmacological, genetic, and molecular evidence showed that $\mathrm{SHB} 1 / \mathrm{HY} 1$ plays an essential role in the tolerance of B toxicity.

\section{MATERIALS AND METHODS}

\section{Plant Materials and Growth Conditions}

All of the Arabidopsis mutagenic or T-DNA insertion mutants and transgenic plants used in this study were in a Col-0 (Columbia) background except for phyAphyB, which was in a Ler (Landsberg) background. The mutants hy1-100 (CS236), phyAphyB (CS6224), ho2 (SALK_113008), ho3 (SALK_034321), ho4 (SALK_044934), bor4-1 (SALK_135095), and bor4-5 (WiscDsLox233D10) were obtained from the ABRC (Arabidopsis Biological Resource Center). The hy1-101 (Zhai et al., 2007) and hy5-215 (Oyama et al., 1997) mutants were described previously.

The seeds were surface sterilized with $10 \%$ sodium hypochlorite solution for $10 \mathrm{~min}$ and washed five times with sterile water, then grown on solid half-strength Murashige and Skoog (1/2 MS) medium (Sigma-Aldrich) supplemented with $1 \%(\mathrm{w} / \mathrm{v})$ sucrose, $0.05 \%(\mathrm{w} / \mathrm{v}) \mathrm{MES}$, and $1 \%(\mathrm{w} / \mathrm{v})$ agar, with or without boric acid. After cold treatment at $4^{\circ} \mathrm{C}$ for 2-4 days in the dark, the plates were transferred into a controlled growth chamber at $21-22^{\circ} \mathrm{C}$ under cool-white fluorescent light (80-100 $\left.\mu \mathrm{mol} \mathrm{m} \mathrm{m}^{-2} \mathrm{~s}^{-1}\right)$ in a long-day photoperiod $(16 \mathrm{~h}$ light/8 h dark).

\section{Mutant Screening}

Ethyl methanesulfonate-mutagenized M2 Col-0 seeds were grown on 1/2 MS medium supplemented with $2 \mathrm{mM} \mathrm{B}$ and seedlings were screened for inhibited primary root growth. The shb1 mutant after three rounds of backcrossing to Col-0 wild-type was used for phenotype analysis and the generation of a mapping population.

\section{Map-Based Cloning}

For map-based cloning of the shb1 locus, 716 F2 mapping plants segregated from the cross of the $\operatorname{shb} 1$ mutant and wildtype Ler were used to delimit the boundaries of the locus with simple sequence length polymorphism markers as listed in Supplementary Table S1 (Pǎcurar et al., 2012).

\section{Seed Germination Measurement}

Germination assay was performed as described by Millar et al. (2006). Seeds germinating on plates containing various boron concentrations were scored, and germination proportion was analyzed at different time points.

\section{RNA Isolation and Gene Expression Analysis}

mRNA levels were measured by quantitative RT-PCR and semiquantitative RT-PCR. Total RNA was extracted from the plant materials using Trizol Reagent (Invitrogen) according to the manufacturer's instructions. Light absorption values of RNA were 
measured using a NanoDrop spectrophotometer. The overall quality of total RNA was evaluated by formaldehyde-RNA denaturing electrophoresis and the A260/A280 ratio.

First-strand cDNA was synthesized with $1 \mu \mathrm{g}$ of total RNA using M-MLV reverse transcriptase and an oligo(dT)15 primer (Takara) in a $10 \mu \mathrm{l}$ mixture. The reaction was then diluted twofold with nuclease-free water, and the cDNA was used as a template for both semi-quantitative RT-PCR and quantitative RT-PCR. For the semi-quantitative PCR analysis, $1 \mu l$ of each reverse transcription reaction was used per PCR reaction in a final volume of $20 \mu \mathrm{l}$. Semi-quantitative RTPCR was performed with gene-specific primers (Supplementary Table S1), and various cycle numbers were tested to determine the logarithmic phase of amplification for each gene. AtACTIN8 was used as the reference gene. The RT-PCR experiments were repeated three times independently, and similar results were obtained. Real-time PCR was performed using the SYBR green PCR master mix (Takara) and run in a Bio-Rad iQ5 real-time PCR detection system. AtACTIN8 was used as the reference (Ohkama-Ohtsu et al., 2004). The primer sequences were given in Supplementary Table S1. All reactions were repeated at least three times. Statistical analysis of the results of real-time PCR was performed using the $2^{-\Delta \Delta C t}$ method.

\section{Plasmid Constructions and Plant Transformation}

pCAMBIA1302 was used to generate p35S::SHB1:GFP (green fluorescent protein) and pSHB1::SHB1:GFP constructs. A 846 bp fragment of the $S H B 1$ coding region was obtained by amplifying from the wild-type cDNA using the following primers: SHB1-NcoI-F (5'- CATGCCATGGCGTATTTAGCT CCGA-3') and SHB1-SpeI-R (5'-GACTAGTGGACAATATG AGACGAAGTATCTC- $3^{\prime}$ ). Restriction sites for NcoI and SpeI are underlined. Primers pSHB1-HindIII-F (5'-CCC AAGCTTTCTTCTCGTTGCCACCGTT- $\left.3^{\prime}\right)$ and $p S H B 1-N c o I-R$ (5'-CATGCCATGGGGTTTGATCGGAATAGAAAAATG-3') were used to amplify a genomic DNA fragment containing the SHB1 promoter. The fragment $(\sim 1200 \mathrm{bp})$ was amplified from wild-type genomic DNA, including HindIII and NcoI restriction sites (underlined). The promoter fragment was then recombined into $p C A M B I A 1302$ to obtain $p S H B 1:: S H B 1: G F P$. Transgenic lines were generated using Agrobacterium tumefaciens LBA3101 by the floral dip method (Clough and Bent, 1998). Seeds of the T1 generation were sown on 1/2 MS medium containing $25 \mathrm{mg} / \mathrm{L}$ hygromycin B (Roche), and T3 homozygous lines were used for further experiments.

\section{Determination of B Content}

Whole roots of 21-day-old seedlings were harvested from 100 to 200 individual plants grown vertically on medium containing $0.05 \mathrm{mM} \mathrm{B}$ and from 300 to 500 plants grown on medium containing $2 \mathrm{mM} \mathrm{B}$. The samples were dried at $60^{\circ} \mathrm{C}$ for at least 3 days, digested with concentrated (13 M) nitric acid, and $\mathrm{B}$ content measured using inductively coupled plasma-mass spectrometry as previously described (Takano et al., 2002).

\section{RESULTS}

\section{The shb1 Mutant Is Hypersensitive to Excessive B Stress}

In order to identify novel boron tolerance-related mutants, we set up a genetic screen for Arabidopsis mutants with altered responses to high concentration of boric acid $(2 \mathrm{mM})$ by root growth inhibition assay. A mutant named shb1 (sensitive to high-level of boron 1) was initially isolated for its dramatically inhibited primary root growth under excessive boron treatment (Figure 1A).

Further characterization indicated that, on average, roots of the shb1 seedlings were about $20 \%$ shorter than those of the wild-type seedlings when growing on regular MS medium (0.05 mM B) (Figure 1A) but were inhibited much more significantly in the presence of additional $B$ from 1 to $4 \mathrm{mM}$ (Figures 1A,B). Because excess B delayed wild-type seed germination, and decreased the germination ratio of shb1 seeds by about $20 \%$ at the $72 \mathrm{~h}$ after planting (Supplementary Figures $\mathrm{S} 1 \mathrm{~A}, \mathrm{~B})$, seedlings with similar growth status were transferred to MS plates containing different concentrations of boric acid to eliminate the interference of different germination rates, and the result was consistent with our previous observation that the primary root elongation of $\operatorname{shb} 1$ was dramatically inhibited by high levels of B (Figure 1C).

In contrast to excessive boron treatments, the shb1 seedlings only exhibited slightly higher primary root inhibition by high salinity than the wild-type seedlings, and no significant difference was observed between the mutant and wild-type roots under B deficiency and mannitol-induced osmotic stress (Figure 1D).

Long hypocotyl is another obvious phenotype of $\operatorname{shbl}$ (Figure 1A). However, the shb1 hypocotyl growth was not affected by high concentrations of boron (Figure 1A). Thus this phenotype might not be related to $\mathrm{B}$ response.

\section{SHB1 Encodes Heme Oxygenase 1, a Key Enzyme that Functions in Heme Metabolism}

Genetic analysis indicated that shb1 was a single-gene recessive mutant, because the F1 plants from a cross between $\operatorname{shbl}$ and wild-type plants were normal, and F2 progeny segregated as wild-type to $\operatorname{sh} b 1$ mutants with a 3 to 1 ratio (Supplementary Figures S2A-C). SHB1 was first mapped on chromosome 2 between the markers UPSC_2-1181 and UPSC_2-18980. Fine mapping delimited SHB1 between markers UPSC_2-10851 and UPSC_2-11823 (Supplementary Figure S2D). One of the open reading frames within this interval is the previously reported HY1 (AT2G26670), which encodes heme oxygenase 1 (HO1). Since the hyl mutant is morphologically similar to $\operatorname{shb1}$ (Davis et al., 1999; Muramoto et al., 1999; Zhai et al., 2007), HY1 is a likely candidate for SHB1. Sequence analysis of genomic DNA fragments covering the $H Y 1$ coding region in shb1 revealed a single $\mathrm{G}$ to $\mathrm{A}$ nucleotide substitution resulting in the change of the tryptophan codon (TGG) to a stop codon (TGA) at amino acid 232, causing premature termination of the translated protein (Figure 2A). 
A
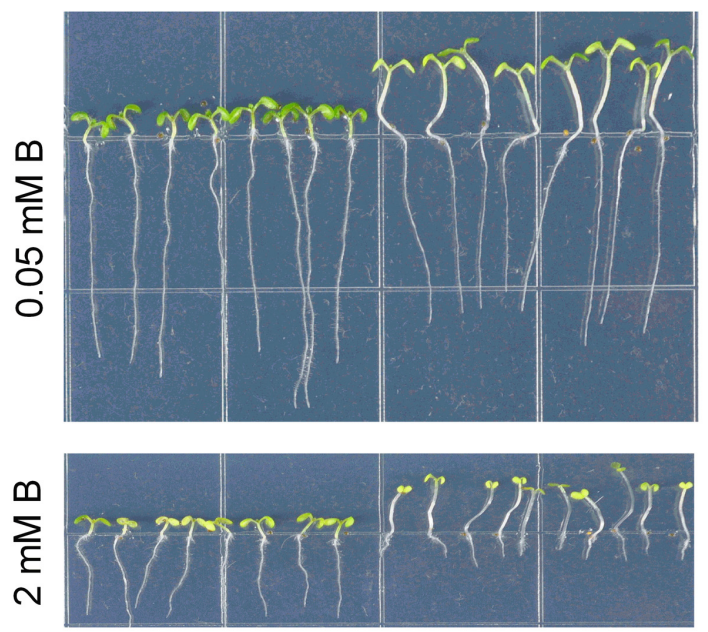

WT

C

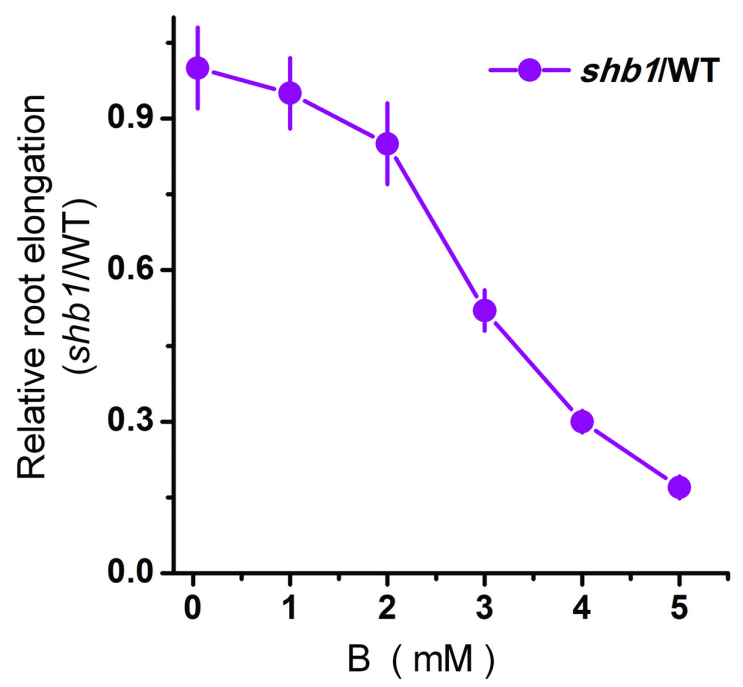

B

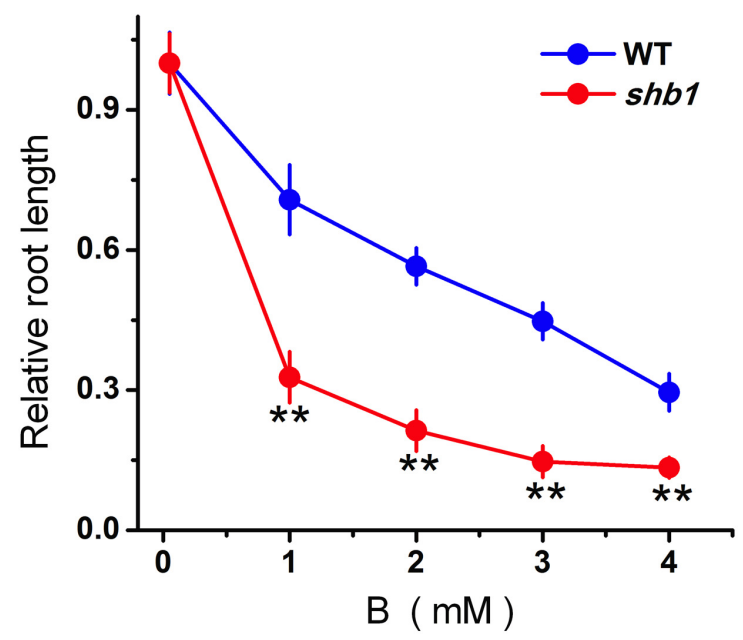

D

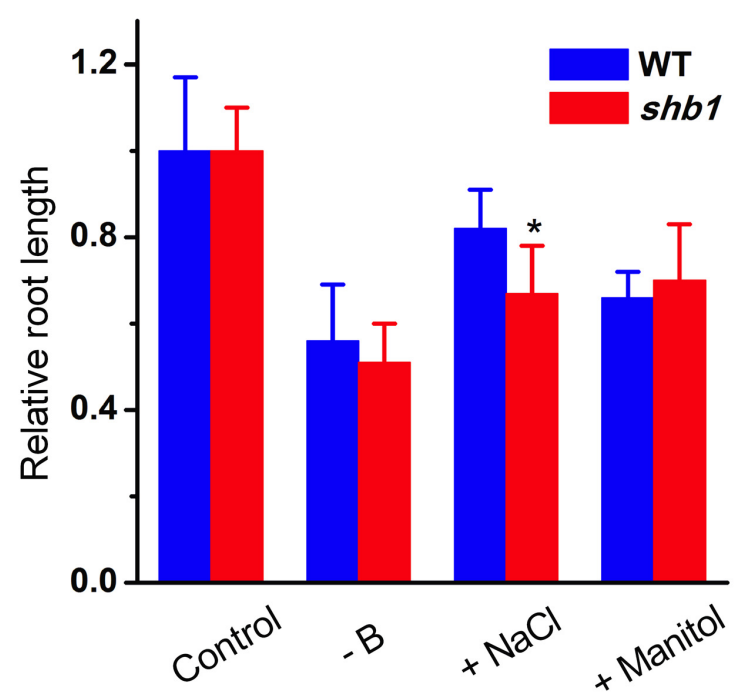

FIGURE 1 | Phenotypes of Arabidopsis shb1 mutants under excessive boron stress. (A) Wild-type Col-0 and shb1 seedlings grown on medium containing $0.05 \mathrm{mM}$ (top) or $2 \mathrm{mM}$ (bottom) B for 10 days. (B) Dose-dependent effects of B on growth inhibition of roots in wild-type and shb1 seedlings. The relative root length of 10-day-old seedlings grown on medium containing various concentrations of $B(0.05,1,2,3$, or $4 \mathrm{mM})$ were measured. (C) Comparative analysis of shb1 root elongation in response to B. Five-day-old wild-type and shb1 seedlings were transferred to medium containing $0.05,1,2,3,4$, and 5 mM B and incubated for another 7 days. The ratio between shb1 and wild-type root elongation was plotted, and the ratio at $0.05 \mathrm{mM} \mathrm{B}$ was defined as 1. (D) Sensitivity of wild-type and shb1 seedlings to other stress conditions such as B deficiency ( $0.003 \mathrm{mM} \mathrm{B})$, osmotic stress ( $300 \mathrm{mM}$ mannitol), and high salinity ( $90 \mathrm{mM} \mathrm{NaCl).} \mathrm{The} \mathrm{relative} \mathrm{root}$ length data are expressed as means $\pm S D(n>10)$ relative to the values obtained under normal conditions with three replicates for each concentration point. Asterisks indicate the significant difference between shb1 mutants and wild-type under B treatments (Student's $t$-test, ${ }^{*} P<0.05,{ }^{* *} P<0.01$ ).

Phenotype analysis of hyl alleles strongly supported our mapping and sequencing results. Both hyl-100 and hy1-101 (Davis et al., 1999; Zhai et al., 2007) exhibited similar phenotypes to that of shb1, with long hypocotyl and hypersensitivity of root growth to excessive B (Figures 2B,C).

Furthermore, a cDNA fragment containing the entire HY1 coding region and a $1.2 \mathrm{~kb}$ upstream genomic DNA fragment was introduced into the shb1 mutant for complementation testing.
The transgenic plants showed no obvious difference from the wild-type plants in growth and development (Supplementary Figures S3A-C) on either normal or excessive B medium. These data indicate that the shb1 mutant is a new allele of the hy1 mutant.

There are four HOs in the Arabidopsis genome (Gisk et al., 2010), so we investigated the possible functional redundancy among these genes. Compared with the other three genes, 
A

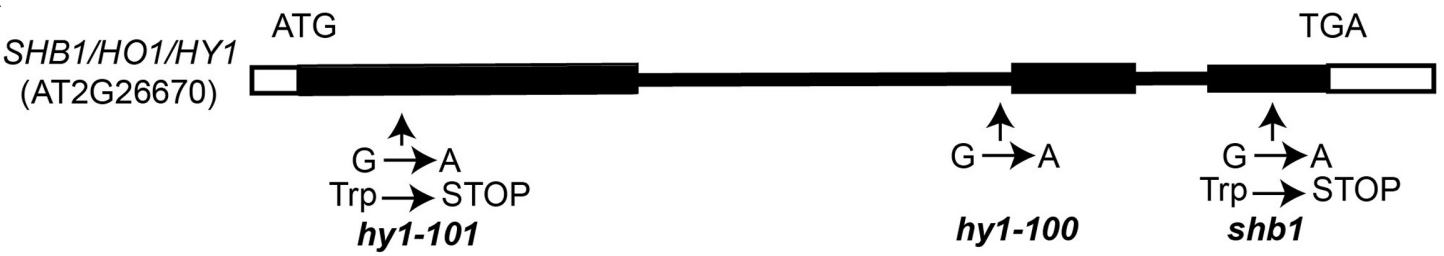

B

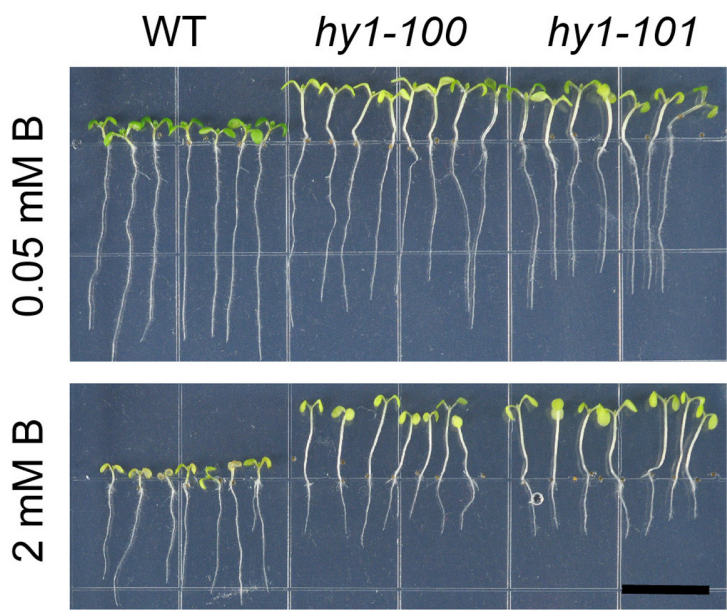

C

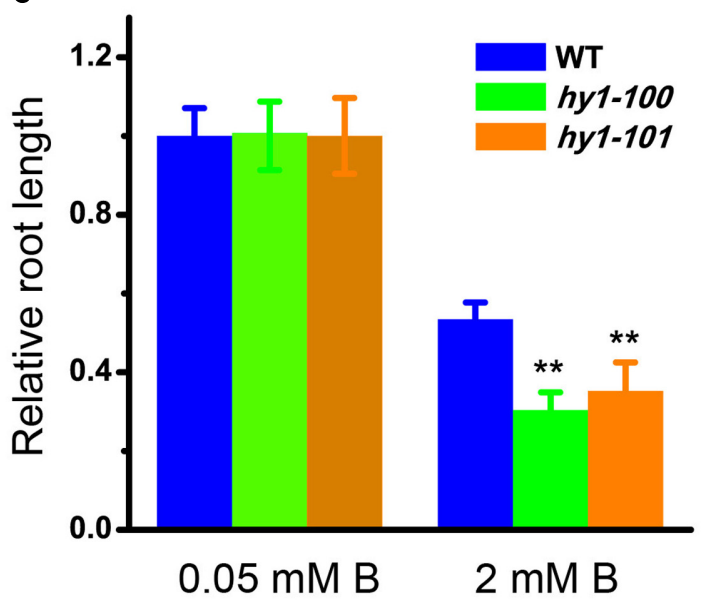

FIGURE 2 | Molecular characterization of SHB1. (A) Diagram of SHB1 genomic structure. Black and white boxes indicate coding regions and untranslated regions, respectively. Sites of the shb1, hy1-100, and hy1-101 mutations are shown. (B) Excessive B-dependent short root phenotypes of hy1-100 and hy1-101 mutant seedlings are shown. Wild-type and mutant seedlings were grown on medium containing $0.05 \mathrm{mM}$ (top) or $2 \mathrm{mM}$ (bottom) B for 10 days. Bars = $1 \mathrm{~cm}$. (C) Relative root length data as described in (B). The relative root length data are expressed as means \pm SD $(n>10)$ relative to the values obtained under normal conditions with three replicates for each concentration point. Asterisks indicate the significant difference between mutants hy1-100, hy1-101, and wild-type under B treatments (Student's $t$-test, ${ }^{* *} P<0.01$ ).

SHB1/HY1 mRNA is the most enriched in roots according to the public expression database and previous reports (Zimmermann et al., 2004; Xie et al., 2011). Furthermore, none of the HO2, HO3, or HO4 T-DNA insertion mutants (SALK_113008, SALK_034321, and SALK_044934) showed a hypersensitivity to excessive boron (Supplementary Figure S4). So, HO1 might be the major $\mathrm{HO}$ involved in the response of roots to high boron stress.

\section{Promoting SHB1/HY1 Expression Resulted in Better Tolerance to B Toxicity}

The expression of $S H B 1$ in roots was regulated by boron stress in a dosage-dependent way. $S H B 1 / H Y 1$ transcription was induced by up to nearly three times that of the control under mild boron stress $(2 \mathrm{mM}$ ) (Figure 3A). The expression of SHB1 was significantly induced by $2 \mathrm{mM} \mathrm{B}$ at $6 \mathrm{~h}$, peaked at $12 \mathrm{~h}$, and was still more than one fold higher than that of the control after $48 \mathrm{~h}$ of treatment (Figure 3B).

Hematin is a potential inducer of $\mathrm{HO} 1$ and was reported to promote HY1 transcription (Figure 3C) (Xie et al., 2011). Application of hematin partially rescued the growth inhibition of the wild-type roots caused by excessive boron, but had no effect on shb1 roots (Figure 3D).
Moreover, the primary roots of $S H B 1 / H Y 1$ over-expression seedlings (35S:SHB1-1 and 35S:SHB1-2) were significantly longer than those of the wild-type when grown on medium containing $2 \mathrm{mM}$ boron (Figures 3E-G), indicating that a high level of $S H B 1 / H Y 1$ expression could alleviate the inhibition of primary root elongation induced by excessive boron.

\section{The Enzymatic By-Products of HO1, CO, and BR Confer Tolerance to B Stress}

Because HO1 catalyzes the conversion of heme into biliverdin, along with the producing of carbon monoxide $(\mathrm{CO})$ and free iron $\left(\mathrm{Fe}^{2+}\right)$, we speculated that $\mathrm{HO} 1$ might function via its byproducts. We therefore tested the effects of $\mathrm{BR}$ (the subsequent product of biliverdin IXa), CORM-2 (a CO donor), and FeEDTA on B tolerance of the root. Application of Fe-EDTA showed no significant effect on root growth (Figure 4A), while both CORM-2 and BR partially alleviated excessive B-induced inhibition of primary root elongation in wild-type and $s h b 1$ seedlings (Figure 4A). On the other hand, hemoglobin (a CO scavenger) could eliminate the CORM-2 effect of restoring root growth (Figure 4A). Thus, BR and CO might be direct effectors of the HO1-regulated B tolerance.

It was reported that defects in HY1 or HY2 would cause a drop in chromophore production and reduced activity of all 

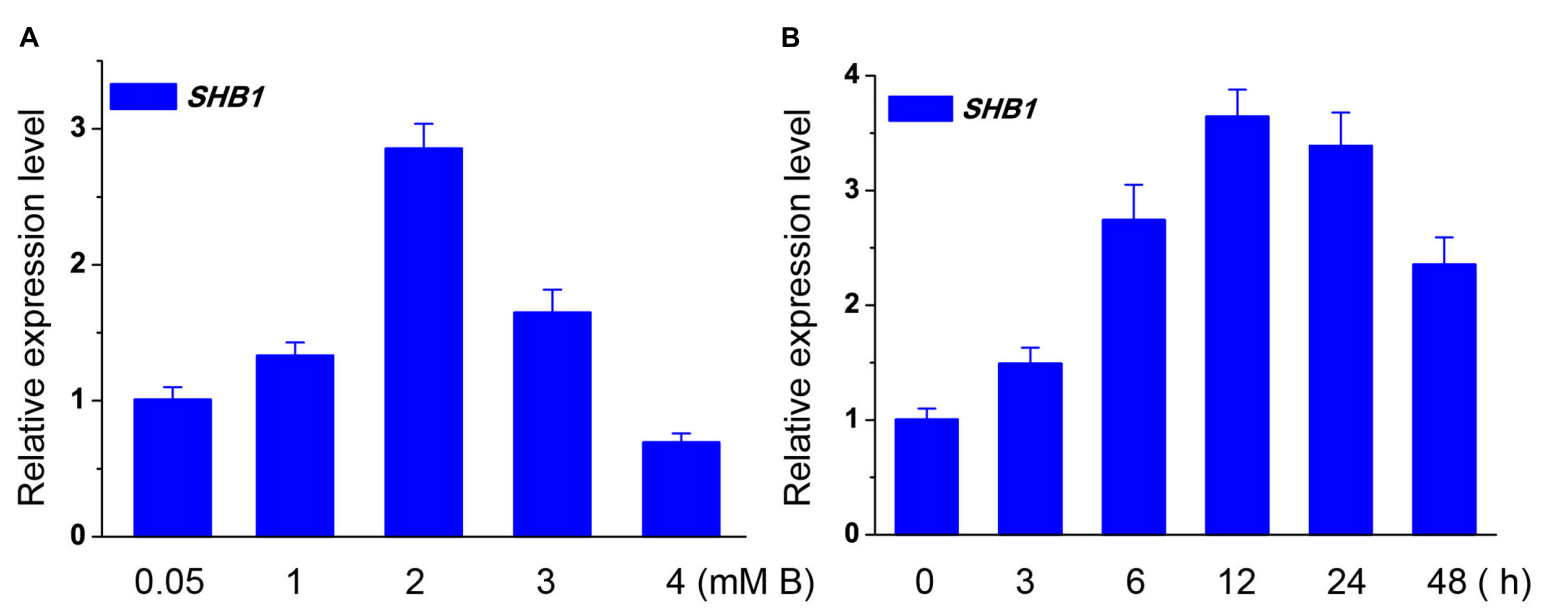

C

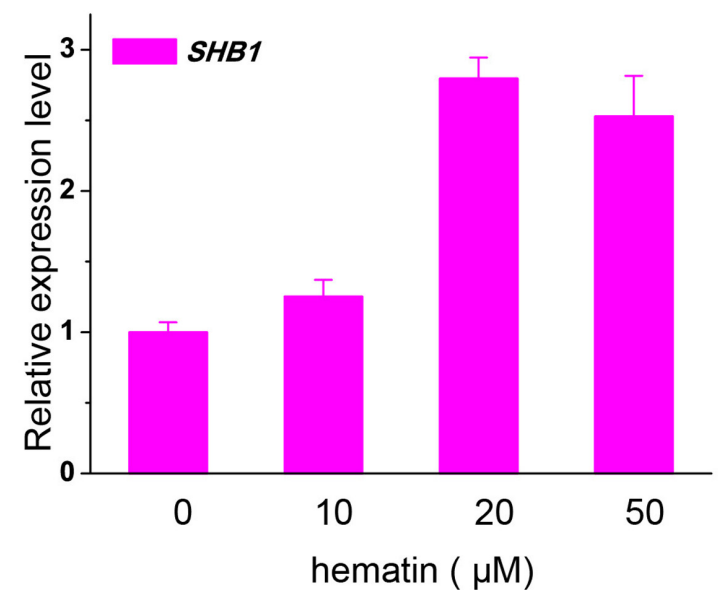

E
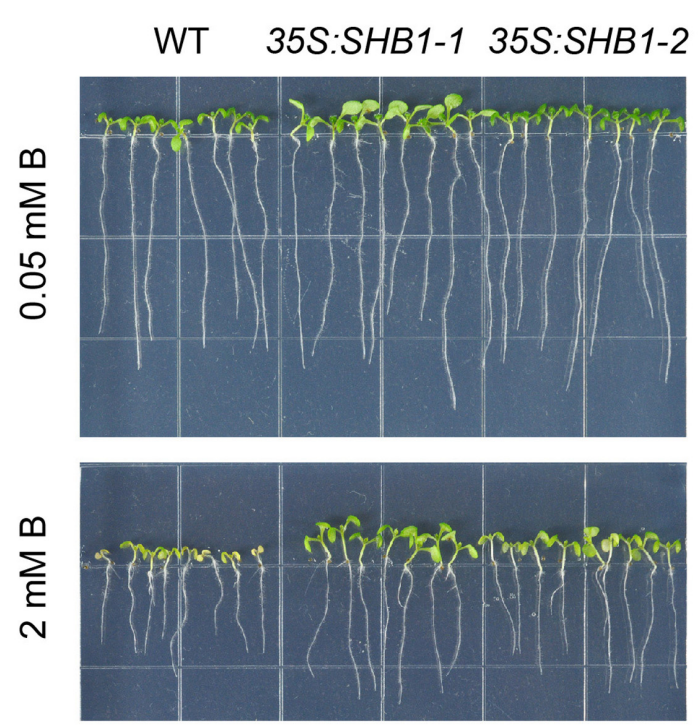

D

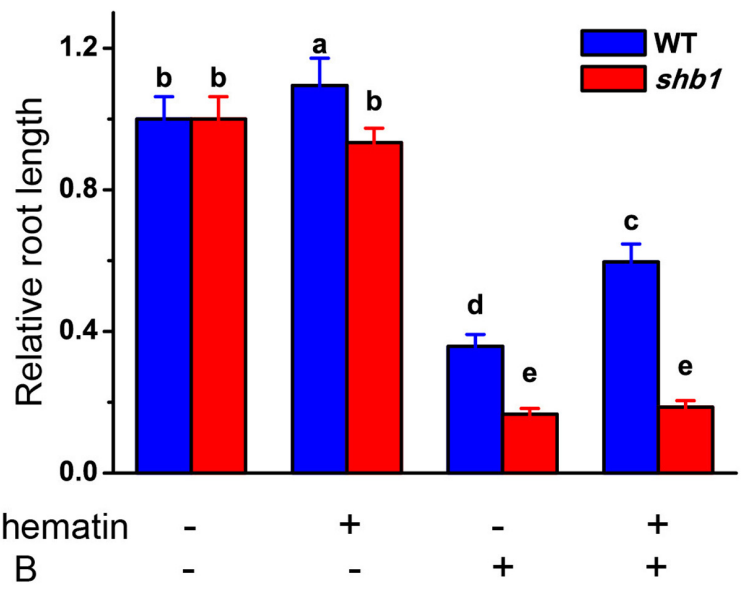

$\mathbf{F}$

SHB1

ACTIN8

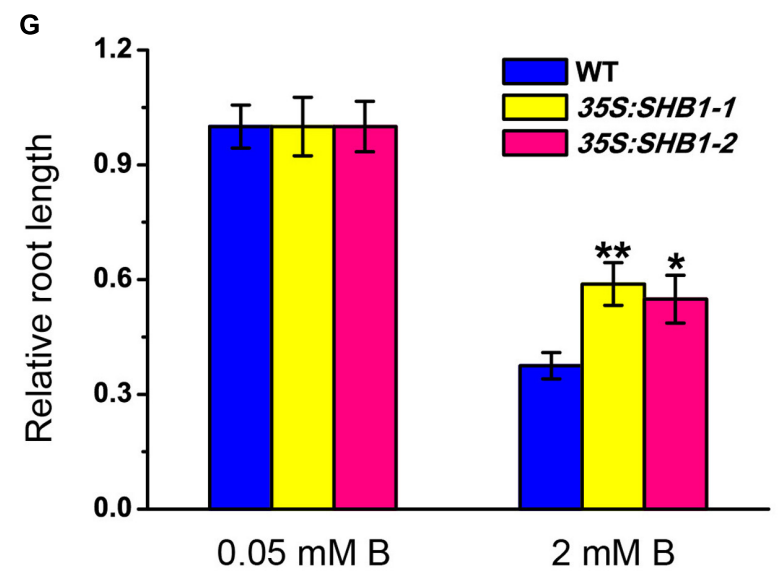


FIGURE 3 | Transcription analysis of SHB1 in response to boron toxicity. (A,B) Quantitative RT-PCR analysis of SHB1 gene expression in wild-type seedlings in response to boron toxicity. (A) Five-day-old wild-type seedlings were transferred to medium containing 0.05, 1, 2, 3, and 4 mM B, respectively, and incubated for $24 \mathrm{~h}$. Data were normalized to ACTIN8 mRNA levels in the same samples and are expressed as means \pm SD ( $n=3$ ). (B) Five-day-old wild-type seedlings were transferred to medium containing $2 \mathrm{mM} \mathrm{B}$ and incubated for $0,3,6,12,24$, and $48 \mathrm{~h}$, respectively. Data were normalized as described in (A). (C) Quantitative RT-PCR analysis of SHB1 gene expression in wild-type seedlings in response to hematin. Five-day-old wild-type seedlings were transferred to medium containing 0, 10, 20, and $50 \mu \mathrm{M}$ hematin, respectively, and incubated for 3 days. Data were normalized as described in (A). (D) Effects of excessive B on root elongation in wild-type and shb1 seedlings with or without $20 \mu \mathrm{M}$ hematin in the medium. Bars with different letters are significantly different at $P<0.05$ according to Tukey's multiple range test. (E) Morphology of wild-type and SHB1 over-expression lines (35S:SHB1-1 and 35S:SHB1-2) subjected to 2mM B for 10 days. (F) SHB1 transcript levels in each SHB1 over-expression line (35S:SHB1-1 and 35S:SHB1-2) under normal growth conditions for 10 days, analyzed by RT-PCR. AtACTIN8 was used as the reference gene. (G) The relative primary root lengths of wild-type and 35S:SHB1-1 and 35S:SHB1-2 seedlings were measured after growth on medium containing 0.05 or $2 \mathrm{mM} \mathrm{B}$ for 10 days. All the data shown are expressed as means $\pm \mathrm{SD}(n>10)$ relative to the value obtained for wild-type plants grown under normal conditions (defined as 1), and asterisks represent significant differences $\left({ }^{*} P<0.05,{ }^{* *} P<0.01\right.$, Student's $t$-test) relative to wild-type.

A
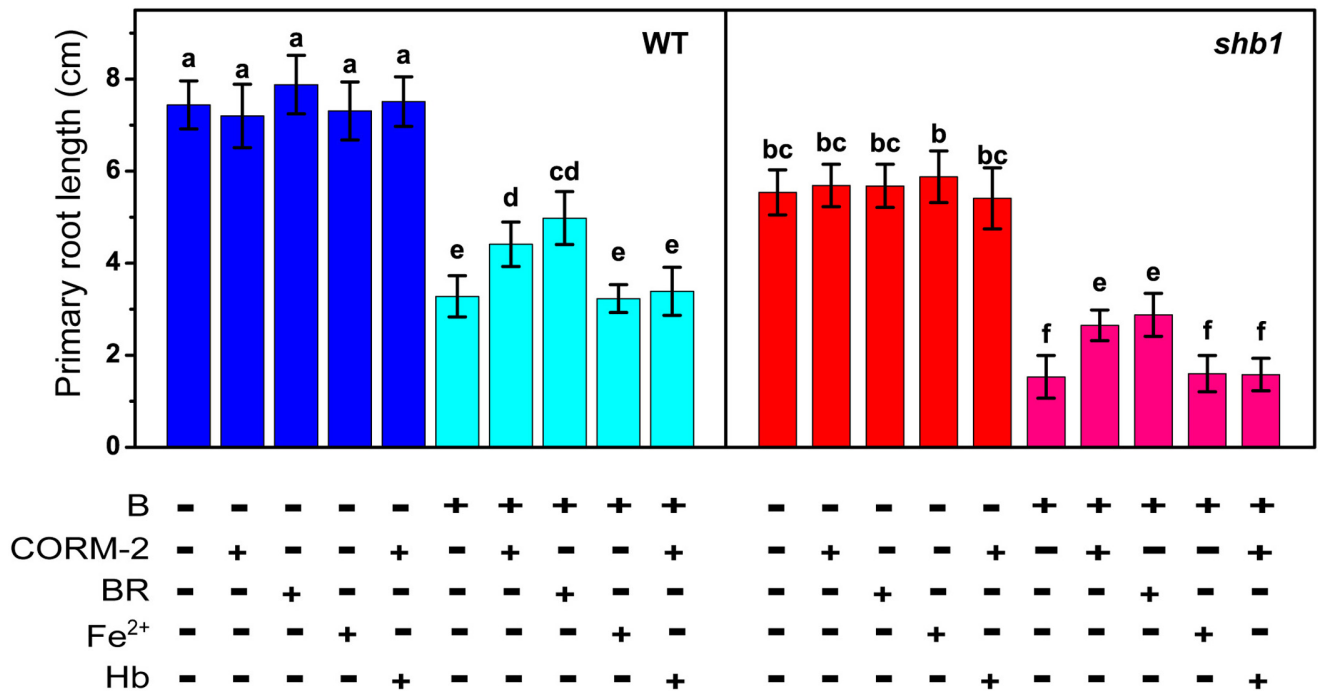

B

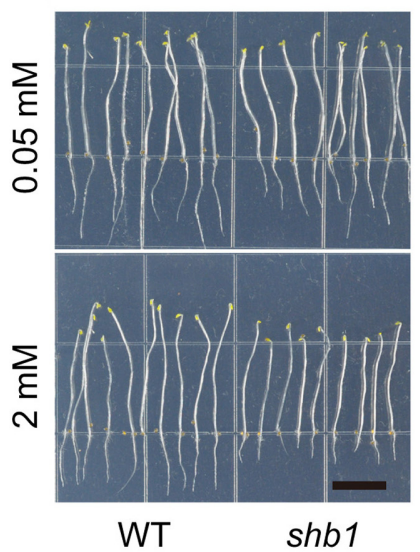

C

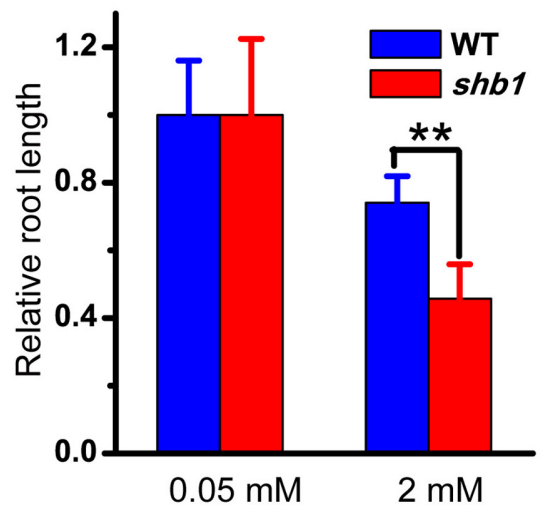

D

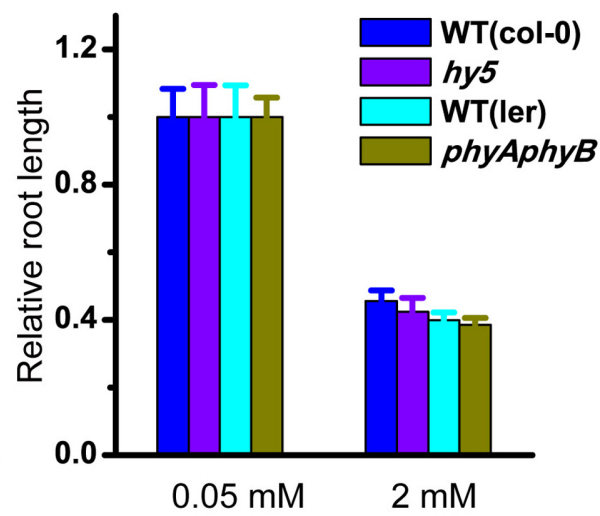

FIGURE 4 | Pharmacological assays of excessive B tolerance in roots. (A) Primary root length of wild-type and shb1 on medium containing varying concentrations of B, $50 \mu \mathrm{M}$ CORM-2, $10 \mu \mathrm{M}$ BR, $50 \mu \mathrm{M}$ Fe-EDTA, $50 \mu \mathrm{M}$ hemoglobin ( $\mathrm{Hb}$ ) or a combination of treatments for 10 days. (B) Sensitive phenotype of shb1 in the skotomorphogenesis process. Wild-type and shb1 seedlings growing on medium containg 2 mM B without light for 10 days. Bars = $1 \mathrm{~cm}$. (C) Relative root length of wild-type and shb1 seedlings grown as described in (B). (D) Relative root length of light signal-related mutants hy5 and phyAphyB on medium containing 0.05 and $2 \mathrm{mM} \mathrm{B}$. All values are means $\pm \mathrm{SD}$ of three different experiments with at least three replicated measurements. Bars with different letters are significantly different at $P<0.05$ according to Tukey's multiple range test in $(\mathbf{A})$, and asterisks represent significant differences (** $P<0.01$, Student's $t$-test) relative to wild-type in (C) 
A

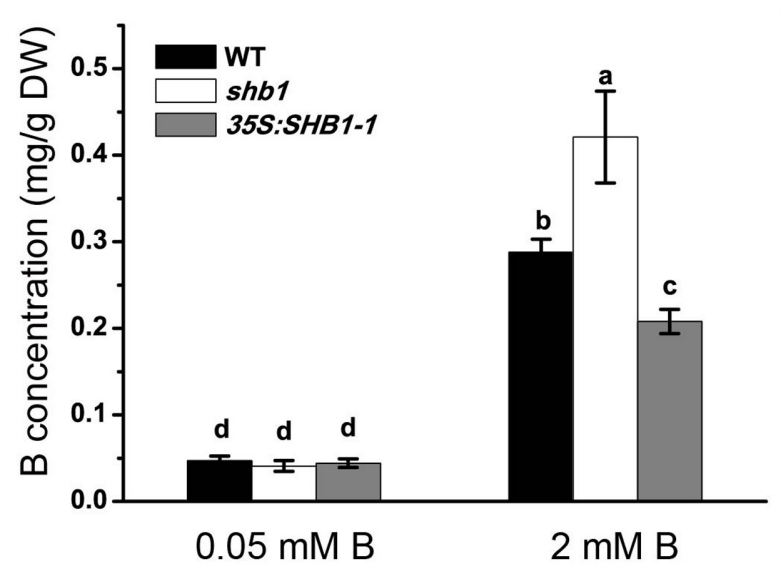

B

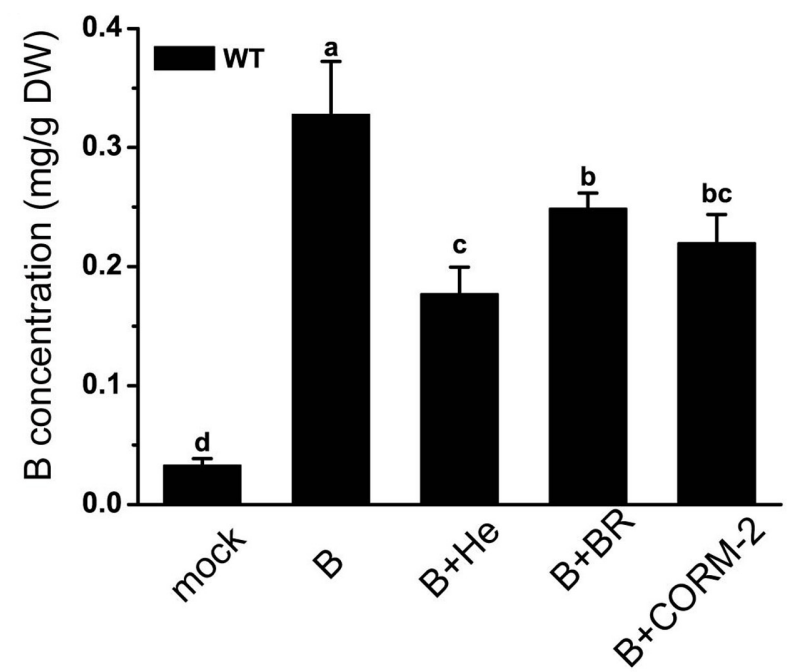

FIGURE 5 | Boron content analysis in roots of wild-type and shb1 mutants. Boron concentrations in roots (A) of wild-type, shb1, and 35S:SHB1-1 seedlings grown on medium containing 0.05 and $2 \mathrm{mM}$ B for 21 days. (B) B concentrations in roots of wild-type seedlings grown on medium containing 0.05 and 2 mM B supplemented with $20 \mu \mathrm{M}$ hematin $(\mathrm{He}), 50 \mu \mathrm{M}$ CORM-2, $10 \mu \mathrm{M}$ BR, and $50 \mu \mathrm{M}$ Fe-EDTA for 21 days. All the data are shown as means $\pm \mathrm{SD}(n=3)$. Bars with different letters are significantly different at $P<0.05$ according to Tukey's multiple range test. DW, dry weight.

phytochrome species (Terry, 1997; Terry et al., 2002). To explore the possible interaction between light and the boron stress response, the shb1 mutants were grown in the dark. However, their roots were still hypersensitive to excessive B similar to those grown in the light (Figures $4 \mathrm{~B}, \mathrm{C}$ ). We then tested the high $\mathrm{B}$ response of phytochrome gene-related mutants (phyAphyB). In our hands, there was no obvious difference in primary root growth between the phyAphyB double mutant and the wildtype (Figure 4D). Our observations preliminarily suggest that $S H B 1$, rather than phytochromes $\mathrm{A}$ and $\mathrm{B}$, mediates Arabidopsis B tolerance. A similar result was obtained with the hy5 mutant, which is defective in an important factor in the light signaling pathway (Figure 4D).

\section{HO1 Enzymatic By-Products Reduce B Accumulation in Roots}

Boron content analysis proved that both shb1 and 35S:SHB1-1 plants had similar levels of $B$ in the roots as that of the wildtype when grown on normal medium (Figure 5A). However, when grown on medium containing $2 \mathrm{mM} \mathrm{B}$, boric acid accumulation in $\operatorname{shb1}$ roots was $45.8 \%$ higher than that in wild-type roots, while that in the $35 S: S H B 1-1$ was $27.8 \%$ lower (Figure 5A).

According to previous reports, the protective effect of $\mathrm{HO} 1$ in plant stress responses could be due to its catalytic products (Noriega et al., 2004; Balestrasse et al., 2005; Sa et al., 2007). We therefore tested the effects of hematin, CORM-2, and BR on reducing $\mathrm{B}$ levels in roots of wild-type seedlings grown on medium containing high levels of boron, and the results revealed that $B$ content in wild-type roots was $0.33 \mathrm{mg} / \mathrm{g}$ dry weight (DW) when grown on medium supplemented with
$2 \mathrm{mM} \mathrm{B}$ and decreased to $0.18,0.25$, and $0.22 \mathrm{mg} / \mathrm{g} \mathrm{DW}$ with addition of hematin, CORM-2, and BR in the medium, respectively (Figure 5B), implying that the products of $\mathrm{HO}$ could significantly lower $\mathrm{B}$ accumulation in roots allowing plants to acquire tolerance of B toxicity.

\section{SHB1/HY1 Decreases B Content in Roots via Induction of BOR4 Expression}

Previous studies have revealed that plants regulate boron content through certain transporters and channels (Takano et al., 2008; Reid, 2014). We compared mRNA levels of some boron transporter and channel genes, including BOR4,BOR1, and NIP5, in wild-type, shb1, and 35S:SHB1-1 roots. WRKY6 was also examined, which was reported to be induced by low B and plays a role under high B conditions (Kasajima et al., 2010). The expression patterns of WRKY6 were not altered in either SHB1-related mutant (Figure 6A).

NIP5 is known to be suppressed by high B levels, and there was no significant difference between wild-type and SHB1-related mutants under either normal or high B conditions (Figure 6A). $B O R 1$ mRNA accumulation was not regulated by high levels of $\mathrm{B}$, and its mRNA levels were not affected by SHB1 (Figure 6A). In contrast, $B O R 4$ could be up-regulated by high $\mathrm{B}$ treatment in the wild-type and 35S:SHB1-1 plants, but failed to be induced in shb1 roots (Figure 6A).

In addition, application of hematin, CORM-2, and BR, but not $\mathrm{Fe}$, in the medium further promoted BOR4 expression in the wild-type under high $B$ conditions (Figure 6B). These data suggested that BOR4 might be downstream of $S H B 1 / H Y 1$, which should be necessary for high B-induced BOR4 expression. 
A
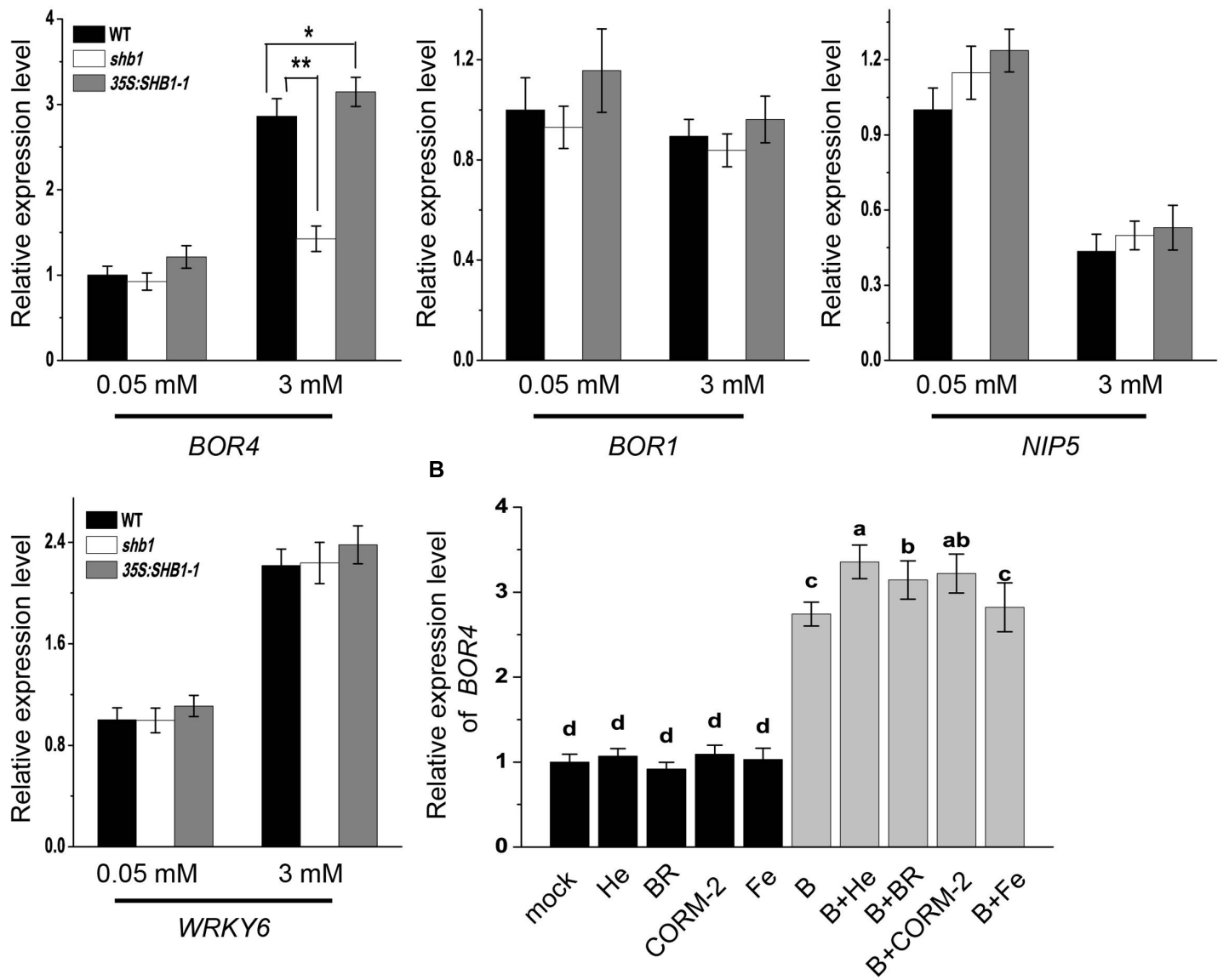

FIGURE 6 | Expression analysis of boron transport-related genes in roots. (A) Quantitative RT-PCR analysis of BOR4, BOR1, NIP5, and WRKY6 gene expression in wild-type, shb1, and 35S:SHB1-1 roots in response to boron toxicity. Five-day-old seedlings were transferred to medium containing 0.05 or 3 mM B and incubated for 2 days. Data were normalized to ACTIN8 mRNA levels in the same samples. Data are shown as means \pm SD ( $n=3$ ), and asterisks represent significant differences ( ${ }^{*} P<0.05,{ }^{* *} P<0.01$, Student's $t$-test) relative to wild-type. (B) Quantitative RT-PCR analysis of BOR4 in roots under excessive B treatment with or without hematin ( $\mathrm{He}), \mathrm{CORM}-2, \mathrm{BR}$, and Fe supplementation. Data were normalized to ACTIN8 mRNA levels in the same samples. Data are shown as means $\pm \mathrm{SD}(n=3)$. Bars with different letters indicate significant differences $(P<0.05)$ according to Tukey's multiple range test.

To further explore the linkage between SHB1/HY1 and BOR4, we obtained two independent T-DNA insertion mutants, bor41 and bor4-5, from ABRC (Figures 7A,B). According to a previous report, although the $B O R 4$ gene is expressed mainly in the roots, the BOR4-defective mutants (bor4-1, bor4-2, and bor4-3) accumulated higher levels of boron in shoots, and the shoots exhibited a striking phenotype (Miwa et al., 2014). In our hands, under long-term excessive B treatment, root growth of the bor4- 1 and bor4-5 mutants was more sensitive compared with that in the wild-type (Figures 7C,D), and the boron content in bor4-1 roots was significantly higher than that in the wild-type (Figure 7F).

As the HO1 inducer hematin could rescue the excessive B-induced root inhibition of the wild-type (Figures 3D, 7E), $\mathrm{B}$ content analysis in root tissues showed that the B level in wild-type roots was $0.31 \mathrm{mg} / \mathrm{g} \mathrm{DW}$ when grown on medium supplemented with $2 \mathrm{mM} \mathrm{B}$, and dropped to $0.21 \mathrm{mg} / \mathrm{g} \mathrm{DW}$ with addition of hematin (Figures 5B, 7F). In contrast, application of hematin had no effect on bor4-1 and bor4-5 root growth (Figure 7E) and failed to reduce B accumulation in bor4-1 roots (Figure $7 \mathbf{F}$ ). These data suggested that $\mathrm{HO} 1$ promotes the exclusion of $\mathrm{B}$ in root cells by up-regulating the expression of the B transporter BOR4.

\section{DISCUSSION}

Excessive boron can be toxic to plants. Identification of genes related to the response to high boron levels will help us to understand the physiological fundamentals of boron toxicity. Sakamoto et al. $(2009,2011)$ isolated several Arabidopsis mutants with root growth defects on medium containing $3 \mathrm{mM} \mathrm{B}$, and indicated that DNA damage is one of the toxic effects caused by excessive $\mathrm{B}$ and that the $H E B 1$ and $H E B 2$ genes might function in this process to promote tolerance of high $\mathrm{B}$. Here, we showed that $\mathrm{HO} 1$ also plays a role in plant tolerance of boron toxicity. 
A

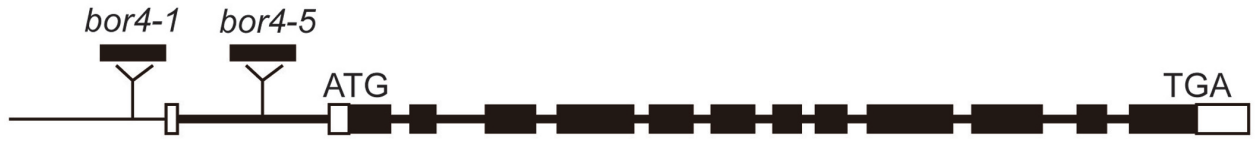

BOR4 (AT1G15460)

$1 \mathrm{~kb}$

B

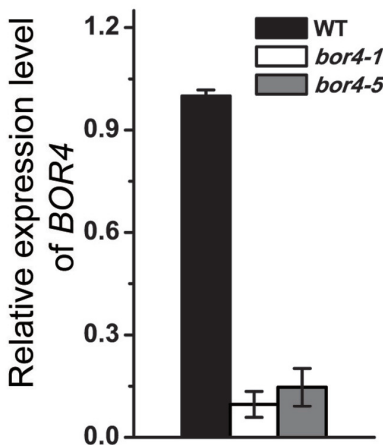

E

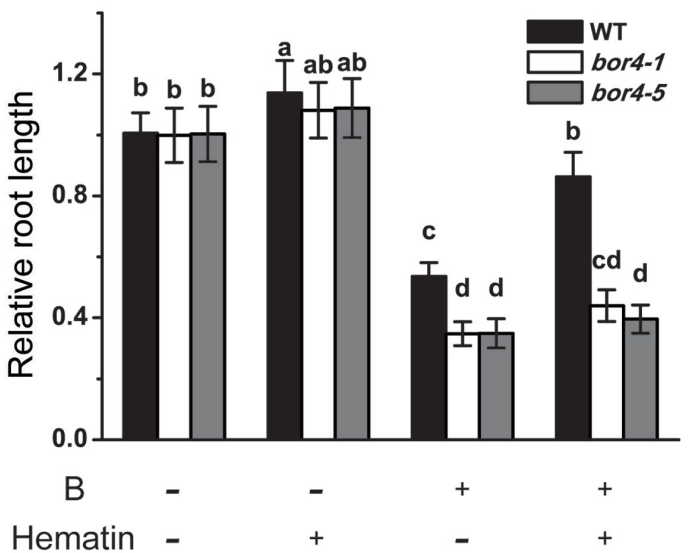

C

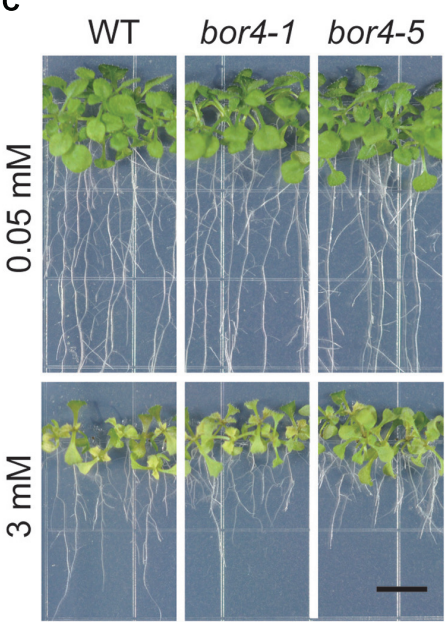

D

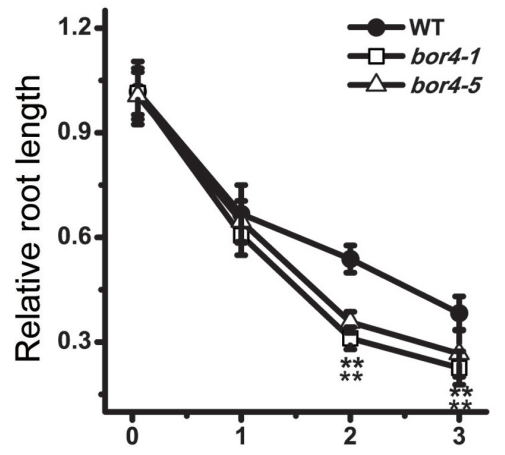

B concentration in medium (mM)

$\mathbf{F}$

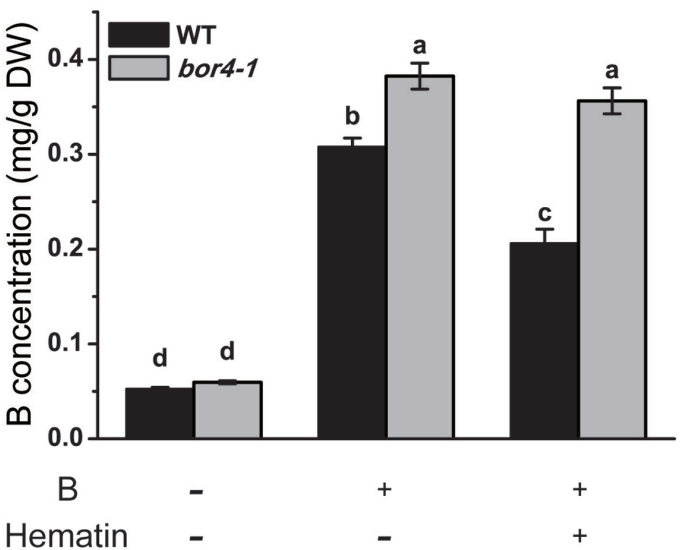

FIGURE 7 | Phenotype analysis of bor4 mutants. (A) Genomic structures of BOR4. Black and white boxes indicate coding regions and untranslated regions of BOR4, respectively. The sites for T-DNA insertion lines are shown. (B) Real-time PCR analysis of BOR4 gene expression in wild-type, bor4-1, and bor4-5 seedlings grown on normal medium. Total RNA was extracted from the whole seedlings of 10-day-old seedlings. Data were normalized to ACTIN8 mRNA levels in the same samples. Data are shown as means \pm SD $(n=3)$. (C) Phenotype of bor4-1 and bor4-5 mutant seedlings under excessive $B$ treatment. Bars $=1 \mathrm{~cm}$. (D) The relative root length of bor4-1 and bor4-5 seedlings grown on medium containing $0.05,1,2$, or $3 \mathrm{mM} \mathrm{B}$ for 21 days. Asterisks represent significant differences $(* * P<0.01$, Student's $t$-test) relative to wild-type. (E) The relative root length of wild-type, bor4-1, and bor4-5 seedlings grown on medium containing 0.05 or $3 \mathrm{mM} B$ with or without $20 \mu \mathrm{M}$ hematin for 21 days. Bars with different letters are significantly different at $P<0.05$ according to Tukey's multiple range test. (F) B content measurement in roots of wild-type and bor4-1 seedlings grown as described in (E). All the data are shown as means \pm SD $(n=3)$. Bars with different letters indicate significant differences $(P<0.05)$ according to Tukey's multiple range test. DW, dry weight.

\section{SHB1/HY1 Is a Necessary Modulator in Mediating Plant Tolerance of Excess B Stress}

In plants, numerous clues have accumulated highlighting that HO1 functions in response to various abiotic stresses. In this study, we provided evidence to demonstrate that $\mathrm{HO} 1$ is necessary in the regulation of boron exclusion and tolerance of excessive boron toxicity in plants.

The shb1 mutant was identified for its hypersensitivity to excessive boron in root growth (Figures 1A,B). SHB1 turned out to be the previously reported $H Y 1$ gene, which encodes $\mathrm{HO} 1$ (Figures 2A-C and Supplementary Figures S2A-D). 
There are four homologous $\mathrm{HOl}$ genes in the Arabidopsis genome (Gisk et al., 2010), and only HO1 shows the highest transcriptional level in roots (Zimmermann et al., 2004; Xie et al., 2011). Single mutants of $\mathrm{HO} 2$, 3, or 4 did not show any hypersensitivity to high levels of B (Supplementary Figure S4), so it is most likely that $\mathrm{HO}$, rather than the other HOs, is a major player in plant tolerance to excess B stress in roots. We showed that promoting the expression of $S H B 1 / H Y 1$ either by application of hematin or by constitutive over-expression of the $S H B 1 / H Y 1$ gene resulted in greater resistance to excessive $\mathrm{B}$ treatment (Figures 3D,E,G).

It has been suggested that $\mathrm{HO} 1$ expression or/and activity could be induced by certain stress conditions, and its protective effect during plant stress responses is due to the products of its catalytic actions (Noriega et al., 2004; Balestrasse et al., 2005; Sa et al., 2007). Our results also supported this hypothesis that $\mathrm{CO}$ and $\mathrm{BR}$ can rescue the high-boron hypersensitivity of shb1 (Figure 4A), while the CO scavenger hemoglobin eliminated the CORM-2 effect (Figure 4A).

We further explored the possibility of light being involved in the boron stress response. Even though we cannot completely rule out the involvement of light signaling in excess $B$ tolerance in plants, the insensitive phenotypes of phyAphyB and hy5 mutants under high boron stress (Figures 4A-D) suggested that decreased levels of the $\mathrm{HO}$ catalytic products $\mathrm{CO}$ and $\mathrm{BR}$ is the major cause of the compromised B stress tolerance in shb1 roots.

\section{SHB1/HY1 Maintains B Content in Roots by Modulating the Expression of the Boron Efflux Transporter AtBOR4}

It has been reported that excessive $B$ can inhibit root growth (Sakamoto et al., 2009, 2011), and we found that boric acid content in shb1 roots was higher than that in the wild-type under excessive $\mathrm{B}$ conditions (Figure 5A), implying that the short root phenotype might be due to the abnormally high accumulation of $B$ in roots.

In response to $B$ stress, many plant species can reduce B accumulation via root B exclusion (Hayes and Reid, 2004; Hamurcu et al., 2016), and the B efflux transporter AtBOR4 has been reported to be involved in excluding excessive $B$ to protect plants. The BOR4 gene is inducible by high levels of $\mathrm{B}$, and transgenic plants over-expressing the BOR4 gene show significantly higher resistance to B than wild-type plants (Miwa et al., 2007, 2014; Kajikawa et al., 2011). By contrast, T-DNA insertion mutants of BOR4 show a slight growth reduction under toxic levels of B (Miwa et al., 2014). A study of two different tomato hybrids with different B tolerance showed that the B-tolerant hybrid had significantly higher expression of SlBOR4 in roots (Princi et al., 2016). These data indicate that the expression level of BOR4 might be correlated with plant B tolerance.

Our observation that the BOR4 gene could no longer be induced by high $B$ treatment in the shb1 mutant, while increasing $S H B 1$ expression resulted in higher BOR4 expression under high $\mathrm{B}$ conditions (Figures 6A,B), indicated that $\mathrm{HO} 1$ might be critical in regulating $B O R 4$ transcription and modulating $\mathrm{B}$ exclusion in roots. The lower level of BOR4 expression could explain the high level of B accumulation in shb1 roots.

Similar cases have been reported previously. For example, HO1 could maintain $\mathrm{K}^{+}$homeostasis by up-regulating the transcription of the proton pump-encoding genes AHA1, AHA2, and AHA3, as well as SOS1 (Bose et al., 2013). RNA sequencing analyses have also implied that $S H B 1 / H Y 1$ is a necessary regulator in mediating gene expression changes under drought stress and most strongly activated or repressed genes in hy1-100 were transport-related genes (Xie et al., 2016).

Carbon monoxide is a catalytic product of HO1. In plants, $\mathrm{CO}$ functions as a signaling molecule and has many functions in regulating root growth, stomatal opening and closing, and even reactive oxygen species balance. Li et al. (2013) showed that a solution saturated with $\mathrm{CO}$ gas could reverse leaf chlorosis in Arabidopsis and maize under iron deficiency conditions because the $\mathrm{CO}$ could promote the transcription of iron absorptionrelated genes such as IRTI in roots, thus increasing plant tolerance to iron deficiency stress ( $\mathrm{Li}$ et al., 2013).

We also found that the $\mathrm{HO} 1$ catalytic products $\mathrm{CO}$ and $\mathrm{BR}$ could induce BOR4 transcription, reduce B content in roots, and restore primary root growth under high $\mathrm{B}$ conditions in the wildtype and shb1/hy1 mutants (Figures 4A, 5B, 6B). On the other hand, the $\mathrm{CO}$ scavenger hemoglobin inhibited the relief from high B toxicity (Figure 4A), implying that $\mathrm{CO}$ might play a major role in this process.

Our data, along with previous reports, led to the assumption that the catalytic products of $\mathrm{HO} 1$ are necessary regulators in plant stress responses and function by regulating the transcription of transport-related genes. However, pharmacological, genetics, and other analyses are still needed to further understand the relationship between $\mathrm{CO}, \mathrm{BR}$, and the regulation mechanism of $\mathrm{B}$ transporters.

\section{HO1 Might Be a Molecular Link in Regulating Different Abiotic Stress Responses}

We noticed that mild B stress $(2 \mathrm{mM})$, but not more severe B stress $(4 \mathrm{mM})$, could induce $S H B 1 / H Y 1 \mathrm{mRNA}$ accumulation after $24 \mathrm{~h}$ of treatment (Figure 3A). The promotion of $H Y 1$ gene expression under mild $\mathrm{B}$ stress and the reduction in expression under severe B stress is similar to the pattern observed under salt stress treatment (Zilli et al., 2008; Xie et al., 2011) and might reflect the correlation between $B$ toxicity and salinity stress.

Excessive accumulation of B in semi-arid and arid climates is frequently accompanied by salinity stress due to limited drainage. Therefore, crops are often subjected to both stresses simultaneously (Gupta et al., 1985; Grieve and Poss, 2000). Although, previous reports have indicated that salinity could intensify the effects of B toxicity in certain plant species (Grieve and Poss, 2000), the molecular mechanisms of the response to excessive B and salinity are largely unknown. Our results, together with previous reports regarding the involvement of HY1 expression in salinity stress resistance (Zilli et al., 2008; Xie et al., 2011), suggest that a signal crosstalk exists in plants under 
both stresses, and heme oxygenase might be a hub involved in tolerance of both stresses.

\section{AUTHOR CONTRIBUTIONS}

Y-KH and FB conceived the project. QL and LW designed the experiments. J-ZW contributed the mutant screening and mapping. QL performed all experiments with the help of LW, PL, Y-LC, and JD. QL analyzed the data and wrote the article.

\section{FUNDING}

This work was supported by Chinese National Natural Science Foundation (grant 31100873, to FB).

\section{REFERENCES}

Aquea, F., Federici, F., Moscoso, C., Vega, A., Jullian, P., Haseloff, J., et al. (2012). A molecular framework for the inhibition of Arabidopsis root growth in response to boron toxicity. Plant Cell Environ. 4, 719-734. doi: 10.1111/j. 1365-3040.2011.02446.x

Balestrasse, K. B., Noriega, G. O., Batlle, A., and Tomaro, M. L. (2005). Involvement of heme oxygenase as antioxidant defense in soybean nodules. Free Radic. Res. 39, 145-151. doi: 10.1080/10715760400022319

Blevins, D. G., and Lukaszewski, K. M. (1998). Boron in plant structure and function. Annu. Rev. Plant Biol. 49, 481-500. doi: 10.1146/annurev.arplant.49. 1.481

Bose, J., Xie, Y., Shen, W., and Shabala, S. (2013). Haem oxygenase modifies salinity tolerance in Arabidopsis by controlling $\mathrm{K}(+)$ retention via regulation of the plasma membrane $\mathrm{H}(+)$-ATPase and by altering SOS1 transcript levels in roots. J. Exp. Bot. 64, 471-481. doi: 10.1093/jxb/ers343

Cakmak, I., Kurz, H., and Marschner, H. (1995). Short term effects of boron, germanium and high light intensity on membrane permeability in boron deficient leaves of sunflower. Physiol. Plant. 95, 11-18. doi: 10.1111/j.1399-3054. 1995.tb00801.x

Camacho-Cristóbal, J. J., Rexach, J., and González-Fontes, A. (2008). Boron in plants: deficiency and toxicity. J. Integr. Plant Biol. 50, 1247-1255. doi: 10.1111/ j.1744-7909.2008.00742.x

Chen, X. Y., Ding, X., Xu, S., Wang, R., Xuan, W., Cao, Z. Y., et al. (2009). Endogenous hydrogen peroxide plays a positive role in the upregulation of heme oxygenase and acclimation to oxidative stress in wheat seedling leaves. J. Integr. Plant Biol. 51, 951-960. doi: 10.1111/j.1744-7909.2009.00869.x

Choi, E. Y., Kolesik, P., McNeill, A., Collins, H., Zhang, Q., Huynh, B. L., et al. (2007). The mechanism of boron tolerance for maintenance of root growth in barley (Hordeum vulgare L.). Plant Cell Environ. 8, 984-993. doi: 10.1111/ j.1365-3040.2007.01693.x

Clough, S. J., and Bent, A. F. (1998). Floral dip: a simplified method for Agrobacterium-mediated transformation of Arabidopsis thaliana. Plant J. 16, 735-743. doi: 10.1046/j.1365-313x.1998.00343.x

Davis, S. J., Kurepa, J., and Vierstra, R. D. (1999). The Arabidopsis thaliana HY1 locus, required for phytochrome-chromophore biosynthesis, encodes a protein related to heme oxygenases. Proc. Natl. Acad. Sci. U.S.A. 96, 6541-6546. doi: 10.1073/pnas.96.11.6541

Esim, N., Tiryaki, D., Karadagoglu, O., and Atici, O. (2013). Toxic effects of boron on growth and antioxidant system parameters of maize (Zea mays L.) roots. Toxicol. Ind. Health 9, 800-805. doi: 10.1177/0748233712442729

Findeklee, P., and Goldbach, H. (1996). Rapid effects of boron deficiency on cell wall elasticity modulus in Cucurbita pepo roots. Bot. Acta 109, 463-465. doi: 10.1111/j.1438-8677.1996.tb00599.x

Gisk, B., Yasui, Y., Kohchi, T., and Frankenberg-Dinkel, N. (2010). Characterization of the haem oxygenase protein family in Arabidopsis

\section{ACKNOWLEDGMENTS}

We thank C-Y Li (Institute of Genetics and Developmental Biology, Chinese Academy of Sciences, China), X.W. Deng (Yale University, New Haven, CT, United States), and the ABRC for providing plant materials. We thank L. Zhang (Department of Chemistry, Capital Normal University, China) for the technical support of inductively coupled plasma-mass spectrometry.

\section{SUPPLEMENTARY MATERIAL}

The Supplementary Material for this article can be found online at: http://journal.frontiersin.org/article/10.3389/fpls.2017.00790/ full\#supplementary-material

thaliana reveals a diversity of functions. Biochem. J. 425, 425-434. doi: 10.1042/BJ20090775

Grieve, C. M., and Poss, J. A. (2000). Wheat response to interactive effects of boron and salinity. J. Plant Nutr. 23, 1217-1226. doi: 10.1080/01904160009382095

Gupta, U. C., Jame, Y. W., Campbell, C. A., Leyshon, A. J., and Nicholaichuk, W. (1985). Boron toxicity and deficiency: a review. Can. J. Soil Sci. 65, 381-409. doi: 10.4141/cjss85-044

Hamurcu, M., Hakki, E. E., Demiral, S. T., Özdemir, C., Minareci, E., Avsaroglu, Z. Z., et al. (2016). Extremely high boron tolerance in Puccinellia distans (Jacq.) Parl. related to root boron exclusion and a well-regulated antioxidant system. Z. Naturforsch. C 71, 273-285. doi: 10.1515/znc-2015-0226

Han, B., Yang, Z., Xie, Y., Nie, L., Cui, J., and Shen, W. (2014). Arabidopsis HY1 confers cadmium tolerance by decreasing nitric oxide production and improving iron homeostasis. Mol. Plant 7, 388-403. doi: 10.1093/mp/sst122

Han, Y., Zhang, J., Chen, X., Gao, Z., Xuan, W., Xu, S., et al. (2008). Carbon monoxide alleviates cadmium-induced oxidative damage by modulating glutathione metabolism in the roots of Medicago sativa. New Phytol. 177, 155-166. doi: 10.1111/j.1469-8137.2007.02251.x

Hänsch, R., and Mendel, R. R. (2009). Physiological functions of mineral micronutrients (Cu, Zn, Mn, Fe, Ni, Mo, B, Cl). Curr. Opin. Plant Biol. 12, 259-266. doi: 10.1016/j.pbi.2009.05.006

Hayes, J. E., and Reid, R. J. (2004). Boron tolerance in barley is mediated by efflux of boron from the roots. Plant Physiol. 2, 3376-3382. doi: 10.1104/pp.103.037028

Kajikawa, M., Fujibe, T., Uraguchi, S., Miwa, K., and Fujiwara, T. (2011). Expression of the Arabidopsis borate efflux transporter gene, AtBOR4, in rice affects the xylem loading of boron and tolerance to excess boron. Biosci. Biotechnol. Biochem. 12, 2421-2423. doi: 10.1271/bbb.110629

Kasajima, I., Idea, Y., Hiraib, M., and Fujiwara, T. (2010). WRKY6 is involved in the response to boron deficiency in Arabidopsis thaliana. Physiol. Plant. 139, 80-92. doi: 10.1111/j.1399-3054.2010.01349.x

Kobayashi, M., Matoh, T., and Azuma, J. (1996). Two chains of rhamnogalacturonan II are cross-linked by borate-diol ester bonds in higher plant cell walls. Plant Physiol. 110, 1017-1020. doi: 10.1104/pp.110.3.1017

Li, H., Song, J. B., Zhao, W. T., and Yang, Z. M. (2013). AtHO1 is involved in iron homeostasis in a NO-dependent manner. Plant Cell Physiol. 54, 1105-1117. doi: $10.1093 / \mathrm{pcp} / \mathrm{pct} 063$

Millar, A. A., Jacobsen, J. V., Ross, J. J., Helliwell, C. A., Poole, A. T., Scofield, G., et al. (2006). Seed dormancy and ABA metabolism in Arabidopsis and barley: the role of ABA 8'-hydroxylase. Plant J. 45, 942-954. doi: 10.1111/j.1365-313X. 2006.02659.x

Miwa, K., Aibara, I., and Fujiwara, T. (2014). Arabidopsis thaliana BOR4 is upregulated under high boron conditions and confers tolerance to high boron. Soil Sci. Plant Nutr. 60, 349-355. doi: 10.1080/00380768.2013.866524

Miwa, K., Takano, J., Omori, H., Seki, M., Shinozaki, K., and Fujiwara, T. (2007). Plants tolerant of high boron levels. Science 318, 1417. doi: 10.1126/science. 1146634 
Muramoto, T., Kohchi, T., Yokota, A., Hwang, I., and Goodman, H. M. (1999). The Arabidopsis photomorphogenic mutant hyl is deficient in phytochrome chromophore biosynthesis as a result of a mutation in a plastid heme oxygenase. Plant Cell 11, 335-348. doi: 10.1105/tpc.11.3.335

Nable, R. O., Bañuelos, G. S., and Paull, J. G. (1997). Boron toxicity. Plant Soil 193, 181-198. doi: 10.1023/A:1004272227886

Nielsen, F. H. (2008). Is boron nutritionally relevant? Nutr. Rev. 66, 183-191. doi: 10.1111/j.1753-4887.2008.00023.x

Noriega, G. O., Balestrasse, K. B., Batlle, A., and Tomaro, M. L. (2004). Heme oxygenase exerts a protective role against oxidative stress in soybean leaves. Biochem. Biophys. Res. Commun. 323, 1003-1008. doi: 10.1016/j.bbrc.2004. 08.199

Ohkama-Ohtsu, N., Kasajima, I., Fujiwara, T., and Naito, S. (2004). Isolation and characterization of an Arabidopsis mutant that overaccumulates O-acetyl-LSer. Plant Physiol. 136, 3209-3222. doi: 10.1104/pp.104.047068

O'Neill, M., Ishii, T., Albersheim, P., and Darvill, A. (2004). Rhamnogalacturonan II: structure and function of a borate cross-linked cell wall pectic polysaccharide. Annu. Rev. Plant Biol. 55, 109-139. doi: 10.1146/annurev. arplant.55.031903.141750

Oyama, T., Shimura, Y., and Okada, K. (1997). The Arabidopsis HY5 gene encodes a bZIP protein that regulates stimulus-induced development of root and hypocotyl. Genes Dev. 11, 2983-2995. doi: 10.1101/gad.11.22.2983

Pǎcurar, D. I., Pǎcurar, M. L., Street, N., Bussell, J. D., Pop, T. I., Gutierrez, L., et al. (2012). A collection of INDEL markers for map-based cloning in seven Arabidopsis accessions. J. Exp. Bot. 63, 2491-2501. doi: 10.1093/jxb/err422

Pallotta, M., Schnurbusch, T., Hayes, J., Hay, A., Baumann, U., Paull, J., et al. (2014). Molecular basis of adaptation to high soil boron in wheat landraces and elite cultivars. Nature 514, 88-91. doi: 10.1038/nature13538

Princi, M. P., Lupini, A., Longo, C., Miller, A. J., Sunseri, F., and Abenavoli, M. R. (2016). Long- and short-term effects of boron excess to root form and function in two tomato genotypes. Plant Physiol. Biochem. 109, 9-19. doi: 10.1016/j. plaphy.2016.08.023

Reid, R. (2014). Understanding the boron transport network in plants. Plant Soil 385, 1-13. doi: 10.1007/s11104-014-2149-y

Reid, R. J., Hayes, J. E., Post, A., Stangoulis, J. C. R., and Graham, R. D. (2004). A critical analysis of the causes of boron toxicity in plants. Plant Cell Environ. 25, 1405-1414. doi: 10.1111/j.1365-3040.2004.01243.x

Sa, Z. S., Huang, L. Q., Wu, G. L., Ding, J. P., Chen, X. Y., Yu, T., et al. (2007). Carbon monoxide: a novel antioxidant against oxidative stress in wheat seedling leaves. J. Integr. Plant Biol. 49, 638-645. doi: 10.1111/j.1744-7909.2007.00461.x

Sakamoto, T., Inui, Y. T., and Fujiwara, T. (2009). "Isolation of mutants sensitive to excess boron," in The Proceedings of the International Plant Nutrition Colloquium XVI, (Davis, CA: University of California), 1126-1129.

Sakamoto, T., Inui, Y. T., Uraguchi, S., Yoshizumi, T., Matsunaga, S., Mastui, M., et al. (2011). Condensin II alleviates DNA damage and is essential for tolerance of boron overload stress in Arabidopsis. Plant Cell 23, 3533-3546. doi: 10.1105/ tpc.111.086314

Shekhawat, G. S., and Verma, K. (2010). Haem oxygenase (HO): an overlooked enzyme of plant metabolism and defence. J. Exp. Bot. 61, 2255-2270. doi: $10.1093 /$ jxb/erq074

Shorrocks, V. (1997). The occurrence and correction of boron deficiency. Plant Soil 193, 121-148. doi: 10.1023/A:1004216126069

Sutton, T., Baumann, U., Hayes, J., Collins, N. C., Shi, B. J., Schnurbusch, T., et al. (2007). Boron toxicity tolerance in barley arising from efflux transporter amplification. Science 318, 1446-1449. doi: 10.1126/science.1146853

Takano, J., Miwa, K., and Fujiwara, T. (2008). Boron transport mechanisms: collaboration of channels and transporters. Trends Plant Sci. 8, 451-457. doi: 10.1016/j.tplants.2008.05.007
Takano, J., Noguchi, K., Yasumori, M., Kobayashi, M., Gajdos, Z., Miwa, K., et al. (2002). Arabidopsis boron transporter for xylem loading. Nature 420, 337-340. doi: 10.1038/nature01139

Terry, M. J. (1997). Phytochrome chromophore-deficient mutants. Plant Cell Environ. 20, 740-745. doi: 10.1046/j.1365-3040.1997.d01-102.x

Terry, M. J., Linley, P. J., and Kohchi, T. (2002). Making light of it: the role of plant heme oxygenases in phytochrome chromophore synthesis. Biochem. Soc. Trans. 30, 604-609. doi: 10.1042/BST0300604

Warington, K. (1923). The effect of boric acid and borax on the broad bean and certain other plants. Ann. Bot. 37, 629-672. doi: 10.1093/oxfordjournals.aob. a089871

Wilks, A. (2002). Heme oxygenase: evolution, structure, and mechanism. Antioxid. Redox. Signal. 4, 603-614. doi: 10.1089/15230860260220102

Xie, Y., Mao, Y., Duan, X., Zhou, H., Lai, D., Zhang, Y., et al. (2016). Arabidopsis HY1-modulated stomatal movement: an integrative hub is functionally associated with ABI4 in dehydration-induced ABA responsiveness. Plant Physiol. 170, 1699-1713. doi: 10.1104/pp.15.01550

Xie, Y., Mao, Y., Lai, D., Zhang, W., Zheng, T., and Shen, W. (2013). Roles of NIA/NR/NOA1-dependent nitric oxide production and HY1 expression in the modulation of Arabidopsis salt tolerance. J. Exp. Bot. 64, 3045-3060. doi: $10.1093 /$ jxb/ert149

Xie, Y., Xu, D., Cui, W., and Shen, W. (2012). Mutation of Arabidopsis HY1 causes UV-C hypersensitivity by impairing carotenoid and flavonoid biosynthesis and the down-regulation of antioxidant defence. J. Exp. Bot. 63, 3869-3883. doi: 10.1093/jxb/ers078

Xie, Y. J., Xu, S., Han, B., Wu, M. Z., Yuan, X. X., Han, Y., et al. (2011). Evidence of Arabidopsis salt acclimation induced by up-regulation of HY1 and the regulatory role of $\mathrm{RbohD}$-derived reactive oxygen species synthesis. Plant J. 66, 280-292. doi: 10.1111/j.1365-313X.2011.04488.x

Yang, L., Ji, J., Wang, H., Harris-Shultz, K. R., Abd Allah, E. F., Luo, Y., et al. (2016). Carbon monoxide interacts with auxin and nitric oxide to cope with iron deficiency in Arabidopsis. Front. Plant Sci. 7:112. doi: 10.3389/fpls.2016.00112

Yannarelli, G. G., Noriega, G. O., Batlle, A., and Tomaro, M. L. (2006). Heme oxygenase up regulation in ultraviolet-B irradiated soybean plants involves reactive oxygen species. Planta 224, 1154-1162. doi: 10.1007/s00425-0060297-X

Zhai, Q., Li, C.-B., Zheng, W., Wu, X., Zhao, J., Zhou, G., et al. (2007). Phytochrome chromophore deficiency leads to overproduction of jasmonic acid and elevated expression of jasmonate-responsive genes in Arabidopsis. Plant Cell Physiol. 48, 1061-1071. doi: 10.1093/pcp/pcm076

Zilli, C. G., Balestrasse, K. B., Yannarelli, G. G., Polizio, A. H., Santa-Cruz, D. M., and Tomaro, M. L. (2008). Heme oxygenase up-regulation under salt stress protects nitrogen metabolism in nodules of soybean plants. Environ. Exp. Bot. 64, 83-89. doi: 10.1016/j.envexpbot.2008.03.005

Zimmermann, P., Hirsch-Hoffmann, M., Hennig, L., and Gruissem, W. (2004). GENEVESTIGATOR. Arabidopsis microarray database and analysis toolbox. Plant Physiol. 136, 2621-2632. doi: 10.1104/pp.104.046367

Conflict of Interest Statement: The authors declare that the research was conducted in the absence of any commercial or financial relationships that could be construed as a potential conflict of interest.

Copyright (c) 2017 Lv, Wang, Wang, Li, Chen, Du, He and Bao. This is an open-access article distributed under the terms of the Creative Commons Attribution License (CC BY). The use, distribution or reproduction in other forums is permitted, provided the original author(s) or licensor are credited and that the original publication in this journal is cited, in accordance with accepted academic practice. No use, distribution or reproduction is permitted which does not comply with these terms. 